Article

\title{
Evolution of Guangzhou Biomedical Industry Innovation Network Structure and Its Proximity Mechanism
}

\author{
Kaihuang Zhang ${ }^{1}$, Qinglan Qian ${ }^{1, *}$ and Yijing Zhao ${ }^{2}$ \\ 1 School of Geographical Sciences, Guangzhou University, Guangzhou 510006 China; KH819@outlook.com \\ 2 Guangzhou Lingnan Architecture Research Center, Guangzhou 510030, China; zhaoyijing@gzlarc.com \\ * Correspondence: qianlynn@21cn.com
}

Received: 25 February 2020; Accepted: 18 March 2020; Published: 20 March 2020

check for updates

\begin{abstract}
The topological structure and multidimensional proximity evolution mechanism of Guangzhou biomedical industry innovation network are studied by using cooperative patents and cooperative papers from 1998 to 2018 with Ucinet and PLS-SEM. Research shows: (1) The evolution of the Guangzhou Biomedical Industry Innovation Network can be divided into three stages, which are the primary budding stage of 1998-2005, the steady development stage of 2006-2012, and the rapid development stage of 2013-2018; (2) the number of subjects in the innovation network is increasing, and the types of subjects are constantly increasing. The innovation network has gone from small to large, from closed to open, and from simple to complex. Patents and papers cooperation networks show different characteristics at various stages; (3) the relationship between geographical proximity, cognitive proximity, organizational proximity, and innovation network differs in stages. The interaction of proximity varies with the content of innovation cooperation. Based on this result, we have put forward policy recommendations for different innovative content.
\end{abstract}

Keywords: innovation network; evolution; proximity; biomedical industry; Guangzhou

\section{Introduction}

In the era of knowledge economy, innovation has become a core factor affecting regional competitiveness [1]. Facing the increasingly complex reality of technology, isolated innovation will greatly increase the uncertainty of innovation and the risk of investment [2]. Therefore, the innovative mode of subject interaction has become one of the important ways to promote technological development [3], after Freeman proposed the concept of an innovative network [4]. The composition of networks, the links between actors, the innovation networks' structure and function has been systematically studied by scholars [5-7]. Since the introduction of social network analysis (SNA) in the field of economic geography [8], innovation network researchers made breakthrough in quantification. On this basis, the time evolution characteristics of innovation network elements have become an important issue for economic geographers [9]. In general, this field mainly involves three directions: First, the evolution of network structure in topological relationships, including changes at the node and the network level $[10,11]$; the second is the evolution mechanism of the innovation network structure [12,13]; the third is to focus on the spatial differences of the innovation network structure and evolution mechanism [14,15]. In the researches on the evolution of innovation network structure, proximity is regarded as an important perspective for interpretation by economic geographers. A proximity analysis framework for innovation networks has also been gradually established [16,17].

As a key emerging strategic industry in China, the biomedical industry has received government attention. According to data from Pharma Projects in 2016, China's biomedical research and 
development companies rose from 105 to 147 in 2015, their global share increased from 3\% to $4 \%$. China's biomedicine industry's innovation capability needs to be further improved. In fact, since 2015, the State Council and the State Food and Drug Administration (CFDA) have successively issued supporting policies such as the "Opinions on Reforming the System of Review and Approval of Drugs and Medical Devices" and "Relevant Policies on Encouraging Innovation of Drugs and Medical Devices to Reform the Management of Clinical Trials". Beginning in the second half of 2018, the Chinese government implemented a new plan for volume purchase of generic remedies. In the future, companies which only produce generic drugs will face greater challenges. Recently, China is facing the threat of a new coronavirus. How to improve the innovation capacity of biotechnology companies in China is more important than ever before. An important industrial reality is the investment periods are very long, cooperation has become an effective innovation approach for the entities when facing complex technologies. Therefore, exploring the proximity dynamic mechanism of the Guangzhou biomedical industry innovation network will be beneficial to improve China's biomedical industry innovation capability. This article takes Guangzhou as a research area, because its biomedical industry is prominent in China. About this case, some researchers explored the relationship between innovation performance, knowledge sources, and personal networks from a relatively static perspective [18]. Compared to this, we attempt to answer the following questions in this paper, from the perspective of evolution: What are the evolution characteristics of the Guangzhou Biomedical Industry Innovation Network? How does multidimensional proximity affect the formation of innovation networks?

The structure of this article is as follows. In the next section we review the existing literature, including the structure of innovation networks, multidimensional proximity, and some empirical studies in China; next, the author introduces the overview of the case area selected in this article, and introduces the research data and method of this article; in the fourth part, we analyzed the evolution path of Guangzhou biomedical industry and its network structure changes; in the fifth part, we conduct an in-depth analysis of the multi-dimensional proximity drivers of the network structure; finally, the conclusions of this article and the relevant policy implications.

\section{Literature Review}

\subsection{Innovation Network Structure}

Essentially, an innovation network is the connections among entities. Thus, the structural characteristics of the innovation network need to be understood from a multi-level perspective: On the one hand, the nature, status and small world of entities and the connections among actors is an important perspective; on the other hand, an integrated network which is composed by entities includes specific characteristics such as scale and form is another important perspective.

The different characteristics of the elements in the network play different roles in the network structure. By nature, the company is considered to be the key to understand the essential characteristics of the regional innovation network [19]. Universities and research institutions also occupy an important place in the network [20], the knowledge they hold is especially important in the network. Some studies on China have pointed out that Chinese universities and research institutions mainly focus on basic research and have less participation in applied research [21]; from the perspective of the entities' position in the network, core companies can effectively change the flow of knowledge and the evolution of network structure [22]. Innovation actors with higher network status are more likely to connect with the outside world and enhance the overall strength of the network [23]; from the view of actors' small world characteristics, it is easy for the partners in the network to have a closer relationship. That will promote the network to form a high-density and highly closed overall network structure [24]. In SNA, structural holes, degree centrality, betweenness centrality, closeness centrality, inter-actor distance, and cohesive subgroups are important indicators for characterizing feature-level features.

The characteristics of the network structure are comprehensive which is formed by the subjects in the network and the interconnections among them. From the perspective of SNA, network density and 
centralization can effectively reflect their integrated characteristics. A study of the global photovoltaic industry believes that the network scale and the centralization of the network can effectively promote the flow of factors between innovation subjects and accelerate the evolution of the structure [25]. Evidence from the Italian shoe cluster network supports this view, and their results show that network density, centralization, and regional openness have a positive impact on the innovation performance of the cluster [26]. Some Chinese scholars have pointed out that even in the same industry, the structure of the technical knowledge network and the scientific knowledge network may be very different, so that their evolutionary mechanisms may also be different [27].

\subsection{Proximities and Innovation Network}

Since the French dynamics proposed the concept of proximity, scholars have conducted a lot of discussions on the type of proximity. Scholars generally believe that proximities include geographical proximity, cognitive proximity, organizational proximity, cultural proximity, institutional proximity [28-30]. These proximities are interconnected and their impacts on innovation networks are complex. Therefore, in the study of proximity, a clear framework has still not been established. In this context, Boschma proposed a classification scheme of geographical proximity, social proximity, institutional proximity, and cognitive proximity. Among them, institutional proximity can be divided into organizational relations and institutional and cultural proximity from different levels [16]. At the entities level in the same region, the actors are similar in system and culture [31], and an actor's vertical connection in organizational structure overlaps with social proximity. Therefore, when analyzing the proximity between entities, this paper defines social proximity as horizontal organizational proximity traditional organizational proximity as vertical organizational proximity for analysis.

Geographical proximity refers to the geographic distance of the innovators to other institutions [32]. It can be measured through direct or indirect methods. The geographical agglomeration of innovators promotes the formation of the network and has a positive effect on the occurrence of innovation. Face-to-face communications provide more opportunities for collective learning among the innovators. That promotes tacit knowledge spillover within the geographic scope [16]. Local embeddedness further strengthens the effect of space, and its existence enhances the ability of different subjects to cope with external shocks [33]. Even if other proximity breaks through geographic boundaries, the geographic sensitivity of participants remains [12]. Inter-region collaboration shrinks as distance increases [34].

Cognitive proximity refers to the similar knowledge base and technical level possessed by interconnected network subjects [35]. In reality, the spatial distribution of knowledge networks is uneven [36]. Therefore, scholars have doubted that it is impossible for all enterprises in the region to achieve complete knowledge sharing [37]. The actor's knowledge base and their ability to absorb externally determine whether knowledge (especially tacit knowledge) can flow between entities. It can be said that the role of cognitive proximity can be manifested only when the cognitive foundations of both parties are relatively close [38], a more diverse network can be shaped [39]. However, too close a proximity is also not a good thing. Too low heterogeneity of knowledge will weaken the possibility of inter-entity cooperation and greatly increase the risk of participant path locking [40].

Organizational proximity is the social and organizational relationship of actors within the network. More and more researches prove that innovation networks based on geographical proximity are likely to cause regional path locks and hinder technological progress [41]. The only way to unlock it is to integrate into the new network. Existing researches point out that explicit knowledge is the main content of communication in weak relationships, and tacit knowledge is shared between entities under strong relationships [42]. This means that the distance of social relations affects the content of innovation activities. Close social relations will strengthen trust between the innovators, reduce uncertainty and opportunism in cooperation, and reduce transaction costs in cooperation [43]. For the same reason, "nternalization" of cooperation is a best choice for cooperation between entities in the same organizational relationship [44]. However, it should be noted that excessive organizational proximity will result in a lack of flexible interaction mechanisms between the entities' contacts, and 
over trusted relationships will cause excessive knowledge spillovers that will increase cooperation risks [45].

\subsection{Proximities and Innovation Networks in China}

Research on the relationship between multidimensional proximity and innovation networks in China is relatively limited. However, we clearly know that China, with its vast territory, is constrained by geographic distances across regions [46]. In the same geographical space, the exchange of knowledge can be effectively promoted [47]. The cognitive distance between the subjects will be reduced, and the connection between the two parties will be strengthened $[48,49]$. The degree of connection between subjects is closely related to whether the two actors can trust each other, which affects the occurrence of innovation [50]. In an innovation research on Hangzhou, researchers pointed out that key universities and institutions play a key role in organizational relations and network shaping [51]. From the existing empirical results on theoretical innovation, Chinese researchers believe that similar cultural and linguistic backgrounds will promote communication between the two sides [52]. Some scholars have pointed out that cognitive proximity based on technical distance can promote the formation of knowledge cooperation networks [14]. In general, we are still unclear about the relationship between multi-dimensional proximity and innovation networks at different stages in China. This study will help us to increase the knowledge of this research field.

\section{Data and Method}

\subsection{Case Overview}

The biomedical industry is one of the industries that the Guangzhou government is focusing on. Guangzhou is also an important biomedical industry R\&D basement in Guangdong Province. Guangzhou's pharmaceutical industry has initially formed an industrial structure based on Chinese medicine, chemical medicine and specialty health products. In recent years, with the continuous development of Guangzhou's biomedical industry, a number of emerging biomedical companies have flourished in Guangzhou around the fields of technical research, medical testing and diagnostic treatment. Currently, there are 1163 biomedical companies in Guangzhou. In 2016, the added value of Guangzhou's biological and health industry was 43.119 billion yuan, accounting for $21.6 \%$ of the annual value added of strategic emerging industries in Guangzhou. Research institutes including Guangzhou Institute of Biomedicine and Health, Chinese Academy of Sciences, Sun Yat-Sen University, and Jinan University gathered in Guangzhou. Under the background of good medical resources, Guangzhou Baiyunshan Pharmaceutical, Guangzhou Xiangxue Pharmaceutical Co., Ltd., and Guangzhou Jinyu Medical Co., Ltd. have good reputation in China. In short, Guangzhou is one of the best objects to study the development of local innovation networks in China's biomedical industry. Exploring its network structure and multi-dimensional proximity mechanism is of great significance to enhance the innovation capacity of China's biomedical industry.

\subsection{Data}

To analyze the evolution and its proximity mechanism of innovation network, we have to effectively map the network of Guangzhou biomedical industry. Patents [53], academic papers [34] and collaborative innovation projects [54] have been treated as a reliable data resource in quantitative analysis [48]. However, some scholars argue that this kind of secondary data can only measure a formal relationship between entities, but not informal connections. Therefore, they try to collect primary data by rooster recall [39], working experience [55] to study. We also noticed that some researchers suppose firms in different sections may hold different attitudes toward patent application [56]. In this article, biomedical industry is our research object. To the biomedical firms, they prefer protecting Intellectual Property by applying patents [17]. To the researchers in research institution, prior knowledge is usually attached to academic papers. Thus, we utilize patents and academic papers to measure innovation, 
what we study is the formal innovation networks. The patent in this article comes from the Guangdong Intellectual Property Office. Because the patent has a lag time of about 18 months from the application to publication, the data obtained in this article started in 1998 and ended in September 2018. We obtained a total of 1027 patents; the academic papers data we study are collected from China Biomedical Literature Service System. We selected five sub-themes of "biological science", "drugs and products", "technology and equipment", "disease and pathology", and "health care". The data time is the same as the patent data. A total of 101,572 Chinese literatures and 3207 English literatures were obtained. Among all the literatures, there are 39,242 co-authored papers, accounting for $38.6 \%$ of the total.

\subsection{Method}

\subsubsection{Social Network Analysis (SNA)}

This paper chooses network density and centralization to reflect the integrated network structure and its changing process. We select the effective size of the structural hole, the degree centrality, betweenness centrality, closeness centrality, the distance between the subjects, and the cohesive subgroup to reflect the individual network structure and its changing process. We use Ucinet to complete relevant empirical operations.

Network density. It is used to reflect the closeness of the connections between the actors in the innovation network.

$$
\mathrm{D}=\sum_{i=1}^{n} \sum_{j=1}^{n} x_{i j}^{N} / n(n-1)
$$

Centralization. It is used to reflect the integrated centrality of the innovation network.

$$
C_{N}=\frac{\sum_{i=1}^{n}\left(C_{D_{\max }}-C_{D_{i}}\right)}{\max \left[\sum_{i}^{n}\left(C_{D_{\max }}-C_{D_{i}}\right)\right]}
$$

Degree Centrality. It is used to assess the importance of the actor in the network. The higher the centrality, the more important the actor is in the network.

$$
C_{a}(\mathrm{i})=\frac{C_{b}(i)}{n-1}
$$

Betweenness Centrality. It is used to reflect control ability of actor in the network.

$$
C_{B}=\sum_{j<k} g_{j k}\left(n_{i}\right) / g_{j k}
$$

Closeness Centrality. It is used to reflect actor's ability to avoid other entities' control.

$$
C_{C}=\left[\sum_{j=1}^{n} d\left(n_{i}, n_{j}\right)\right]^{-1}
$$

Distance between entities. In a network, the distance between two entities is the shortest path between them in a matrix sense.

Cohesive subgroup. It is used to discuss that the network is composed of those small groups, and its measurement is based on whether there is a close relationship between the subjects in the subgroup. In this study, we use the concept of K-plexes for definition. K-plexes is a condensed subgroup based on degree centrality, which requires that each actor is directly connected to other partners except $\mathrm{K}$ subjects. If the size of a subgroup is $n$, then the degree of any subject in the set is not less than $\mathrm{n}-\mathrm{K}$. 


\subsubsection{PLS-SEM}

Structural Equation Model (SEM) is a multivariate measure model that considers both the internal structure of influencing factors and the causal relationship between influencing factors. It can tolerate a range of errors between independent and dependent variables, and it can also evaluate the structure and relationship between factors [57]. When theory is relatively lacking, PLS is more applicable to SEM [58]. Based on the characteristics of the data in this paper, we used the PLS analysis method as the parameter estimation method of the model, and calculated it with the Smart-PLS software. PLS-SEM includes two equations, namely measurement equation and structure equation. The measurement formula is as follows:

$$
\eta_{i}=\sum_{i=1} w_{i j} x_{i j}+\delta_{i}
$$

Among them, $\eta_{i}$ is a latent variable. In this article, it refers to the network structural $(\mathrm{N})$, geographical proximity $(\mathrm{G})$, cognitive proximity, organizational proximity, innovation investment (I) and the interaction of multi-proximities. $x_{i j}$ is the index that constitutes the latent variable, $w_{i j}$ is the correlation between each index and the latent variable, and $\delta_{i}$ is the error term of each observation index.

The structural equation is as follows:

$$
\eta_{i}=\sum_{i \neq j} \beta_{i j} \eta_{j}+\zeta
$$

Among them, $\eta_{i}$ is a latent variable. In this paper, exogenous latent variable refers to the network structure. The influence of exogenous latent variables includes geographical proximity, cognitive proximity, organizational proximity, innovation investment and the interaction terms of multi-proximities. Cognitive proximity and organizational proximity are the endogenous latent variables measured; the geographical proximity is the endogenous latent variable that affects them. $\eta_{j}$ refers to other latent variables that affect $\eta_{i}, \beta_{i j}$ refers to the mutual relationship between the latent variables, and $\zeta$ is the error term between the latent variable relationships.

Among the indicators of the network structure of the observed variables, we chose the network density, the degree centrality, and the average effective size of structure hole. Relevant calculation formulas were pointed out. The effective size of structural hole refers to the size of the individual network minus the redundancy, and reflects the non-redundant connection between the two actors. The formula is as follows:

$$
E S_{i}=\sum_{j}\left(1-\sum_{q} p_{i q} m_{j q}\right), q \neq i, j .
$$

$\mathrm{n}$ is the network scale, $\mathrm{j}$ is the actors which is connected with $\mathrm{i}, \mathrm{q}$ is the third subject exclude $\mathrm{i}$ and $\mathrm{j}$, $p_{i q} m_{j q}$ is redundancy between $\mathrm{j}$ and $\mathrm{q}$, and $p_{i q}$ represents a proportion of relationship between $\mathrm{i}$ and $\mathrm{q}$ in all actor i's relationships.

Geographical proximity. Since a considerable part of the patent units are subjects outside Guangzhou or Guangdong, physical distance measurement will have a large deviation. We use nominal geographical proximity to perform indirect measurement to avoid the impact of actual distance. A value of 5 in the same area, a value of 4 in the same area as Guangzhou, a value of 3 in Guangdong not in Guangzhou, a value of 2 in the country, and a value of 1 in the foreign country.

Cognitive proximity. We measure the degree of proximity using the similarity coefficient of industrial structures through the similarity measurement of patent content generated by each subject. The higher the similarity of patent types between units, the closer the cognitive distance [59]. The 
relevant formula is as follows. $X_{i n}$ and $X_{j n}$ represent the amount of actor $\mathrm{i}$ and $\mathrm{j}$ in $\mathrm{n}$ group patent. Technical proximity will eventually be a continuous variable between $0-1$.

$$
S_{i j}=\frac{\sum\left(x_{i n} x_{j n}\right)}{\sqrt{\left(\sum x_{i n}^{2}\right)\left(\sum x_{j n}^{2}\right)}}
$$

Organizational proximity. We check whether there is an internal vertical hierarchical relationship between the cooperative units through enterprise investigation, and sum up the number of relationships, the larger the total, the closer the distance. For collaborative papers, the innovative Guangzhou Bioengineering Center and the Guangzhou Centers for Disease Control and Prevention serve as information exchange platforms to maintain horizontal organizational relationships with subjects. For cooperative patents, it is difficult to determine this. The author believes that the use of the ternary closure model will have a certain degree of distortion, so only the horizontal relationship of the data in the collaborative paper is studied.

The innovation investment will have a certain impact on the development of the network structure, so it is included as a reference variable. The measurement criteria include Guangzhou biotechnology tax exemption and the number of biomedical related policies. The relevant data comes from the Guangzhou Statistical Yearbook and the official website of the government.

\section{The Evolution of Innovation Structure}

\subsection{Stages of Biomedical Industry in Guangzhou}

Reviewing the development of Guangzhou's biomedical industry in the past two decades, combined with patents (In 2002, the first patent in the field of biomedicine appeared in Guangzhou; in 2006 , the number of patents was 14, an increase of $100 \%$ over 2005; in 2013, the number of patents increased by more than $50 \%$ after long-term stabilization), paper publications (The number of papers fluctuated from 1998 to 2005. Since 2006, the number of papers has stabilized at about 5000 and has gradually increased. After 2013, the number of published papers has stabilized at 6000-7000), the number of enterprises (In the long run, the number of enterprises has grown exponentially at a rate of $23 \%$ per year. In each year, we find that the number of enterprises will increase by more than 10 every year after 2008, and more than 20 after 2012), policies and development of industrial park it can be divided into three stages (Figure 1):

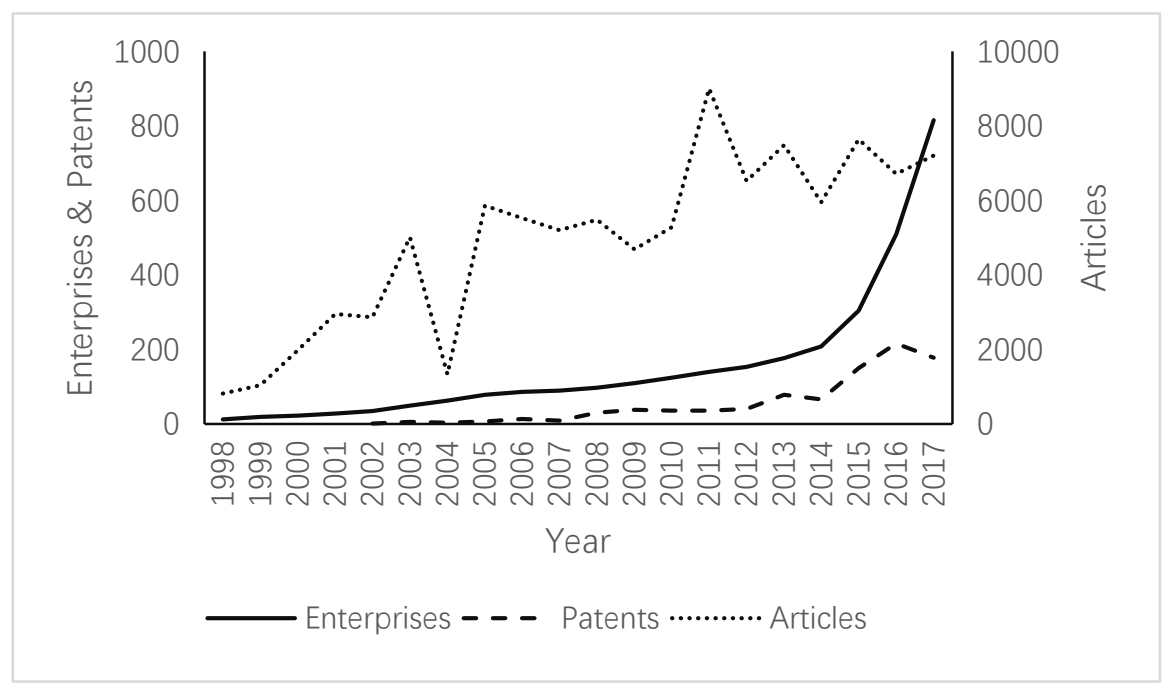

Figure 1. Development of biomedical companies, patents, and papers in Guangzhou. 
(1) The first stage (P1): 1998-2005. At this stage, the biomedical industry was gradually developing as a node, with innovations such as new drugs, patents, and papers develop from scratch; the total number of enterprises established and listed was small, the growth rate is slow; the biotechnology professional park was still under construction. We call this period the primary budding stage.

(2) The second stage (P2): 2006-2012. Taking the breakthrough in 2006 as a key time, Guangzhou's biomedical industrial agglomeration was formed during this period, and a large number of policy documents emerged. The government and enterprises have increased investment in the field, and the total amount of related patents continued to increase. The main characteristics of the stage were policy guidance and steady improvement, but the relevant documents lacked pertinence. Industry-related factors were becoming more complete, and we call this period the steady growth stage.

(3) The third stage (P3): 2013-2018. The characteristics of industrial clusters were obvious, and they obtained professional honorary titles. Various elements of the industry exploded, and a number of implementation documents related directly to biomedicine have been issued. However, since the ability of enterprises as the main body of innovation was still weak during this period, the structure of the innovation network was unstable. Compared to Shanghai and Beijing, there was still a big improvement zone for Guangzhou. Therefore, we call this period the rapid development stage.

\subsection{Typology of Innovators and Their Development}

According to the nature of the innovators, the innovation actors in the Guangzhou biomedical industry cluster can be roughly divided into the following seven categories: (1) Enterprises, mainly including biomedicals, biotechnology-based chemical remedies and traditional Chinese medicine manufacturing, also including biotechnology research and development, biological products, diagnosis and treatment technology, medical raw materials, gene sequencing, basic research, medical equipment and equipment, testing and evaluation, and other enterprises. In practice, the innovation capabilities of biotechnology, biological products, diagnostic and therapeutic technologies, and basic research companies are prominent; (2) universities, include Sun Yat-sen University, Jinan University, South China University of Technology, Guangdong Medical University, and other colleges of medicine and biology; (3)research institutions, include Guangzhou Institute of Biomedicine and Health, Chinese Academy of Sciences, Guangdong South China New Drug Creation Center, South China Stem Cell and Regenerative Medicine Research Center of Academy of Military Medical Sciences, and research institutes affiliated to universities and hospitals; (4) service agencies, include industry organizations and intermediaries, talent associations, foundations, industry alliances, CRO agencies, etc.; (5) hospitals, mainly the top three hospitals in the city; (6) individual, that is, the subject of innovation that appears independently in the application; (7) government.

From the development stage of Guangzhou's biomedical industry innovation: (1) In the primary budding stage, the number of innovators is small. The innovators mainly include pharmaceutical and medical device companies, and only a small number of testing and medical raw material companies. Colleges and universities started to establish affiliated enterprises. Sun Yat-sen University and Jinan University are the mainstay of innovation. Guangzhou Bioengineering Center and other service agencies have begun to establish and play a role. Hospital scientific research is in its infancy. The government approves the construction of related industrial parks through administrative powers. On the whole, the innovation of enterprises is relatively independent, and the industrial chain is incomplete; (2) at the stage of steady development, the number of entities has increased to a certain extent, and there have been more biotechnology companies, biological products and pharmaceutical companies. Guangzhou Institute of Biology and Health plays an important role in scientific research institutes. Industry associations and alliances in sub-sectors have begun to increase. Hospitals are important $\mathrm{R} \& \mathrm{D}$ actors in the areas of treatment and diagnosis. The government has also begun to support the development of the local biomedical industry through policy measures. On the whole, there are many technology outsourcing, the industrial chain is gradually complicated, and the connections scale have increased; (3) during the rapid development stage, the number of subjects has grown rapidly, 
the number of biotechnology research companies has increased, and diagnostic, therapeutic and gene cell research companies have become innovation-led. The number of university and research institutes has also increased rapidly. They become a major leader in the field of medicine. Multi-type service agencies and intermediary agencies are rapidly emerging. Cooperation between hospitals, universities, research institutes and enterprises has increased. The government supports the development of the industry mainly through financial means. In a word, open innovation is increasing, and various entities are actively participating in different links in the industry chain.

\subsection{Evolution of Innovation Networks Structure}

In general, the Guangzhou Biomedical Innovation Network has gone through a process from small to large, from isolation to openness. The types and number of entities participating in innovation are much more diverse and greater, the concentration of network is relatively dense, the ability of innovators to control and avoid is weak at all time, network connections are becoming closer, knowledge exchanges are becoming more frequent, and the number of sub-networks is increasing. However, from the perspective of cooperation content, the network structure of cooperative patents and cooperative papers show different characteristics in different evolution stages (Table 1).

Table 1. Structural Characteristics of Innovation Network at Each Stage

\begin{tabular}{ccccccccc}
\hline & & $\begin{array}{c}\text { Network } \\
\text { Density }\end{array}$ & Centralization & $\begin{array}{c}\text { Degree } \\
\text { Centrality }\end{array}$ & $\begin{array}{c}\text { Betweeness } \\
\text { Centrality }\end{array}$ & $\begin{array}{c}\text { Closeness } \\
\text { Centrality }\end{array}$ & $\begin{array}{c}\text { Actors } \\
\text { Distance }\end{array}$ & $\begin{array}{c}\text { Sub } \\
\text { Networks }\end{array}$ \\
\hline Patents & P2 & 0.1257 & $25.07 \%$ & 0.11 & 0.08 & 0.06 & 1.463 & 2 \\
& P3 & 0.0423 & $101.74 \%$ & 0.40 & 0.19 & 0.03 & 2.077 & 4 \\
Papers & P1 & 0.0571 & $78.46 \%$ & 0.15 & 0.03 & 0.05 & 1.333 & 1 \\
& P2 & 0.0591 & $13.65 \%$ & 0.08 & 0.01 & 0.04 & 1.077 & 6 \\
& P3 & 0.0412 & $12.55 \%$ & 0.17 & 0.01 & 0.03 & 1.218 & 6 \\
\hline
\end{tabular}

(1) Primary budding stage (1998-2005). In 1998, Guangzhou held the first Guangzhou Science and Technology Exchange Conference for Chinese students studying abroad, which attracted a group of biomedical talents to enter Guangzhou. In the same year, Huasheng Gene became the first company in Guangzhou to develop new remedy. In 2000, Guangzhou Guanzhou was designated as an international biotechnology research and production base, the so-called "Bio Island". In 2002, patent applications related to biomedicine began to appear in Guangzhou, and papers in this field began to grow at a rate of over 50\%. Beginning in 2003, Guangzhou has continued to list biomedical companies, and the growth rate of startups has doubled.

Observing the cooperative innovation at this stage, due to the small number of patents, the technical cooperation innovation network was not yet formed. Among the data obtained, there were 15 co-authored papers in the field of biomedicine, and a collaborative innovation network was formed (Figure 2). In terms of scale, the scale of the collaborative paper network at this stage was small, and limited cooperation hindered knowledge exchange between the subjects; in terms of the characteristics of the main actors of the network, universities and research institutes were the main innovators of the network, and the information integration platform was the core of cooperative innovation. At this time, the boundary between the core network and supportive network was not clear; from the perspective of network's structure, the concentration of web was dense, the actors also had great power to connect other entities. However, the innovators' ability to control or avoid otherswas still weak; from the perspective of external network contacts, there were a certain number of partners from other regions like Shenzhen, Shunde and Zhejiang. This shows that the theoretical innovation in Guangzhou's biomedical field has been nested in the regional innovation network since its infancy. In addition, the close relationship between the Guangdong Institute of Medical Intelligence and Guangzhou Yantang Biochemical Co., Ltd. reflects that industry-academia cooperation in specific fields can be effectively promoted. 


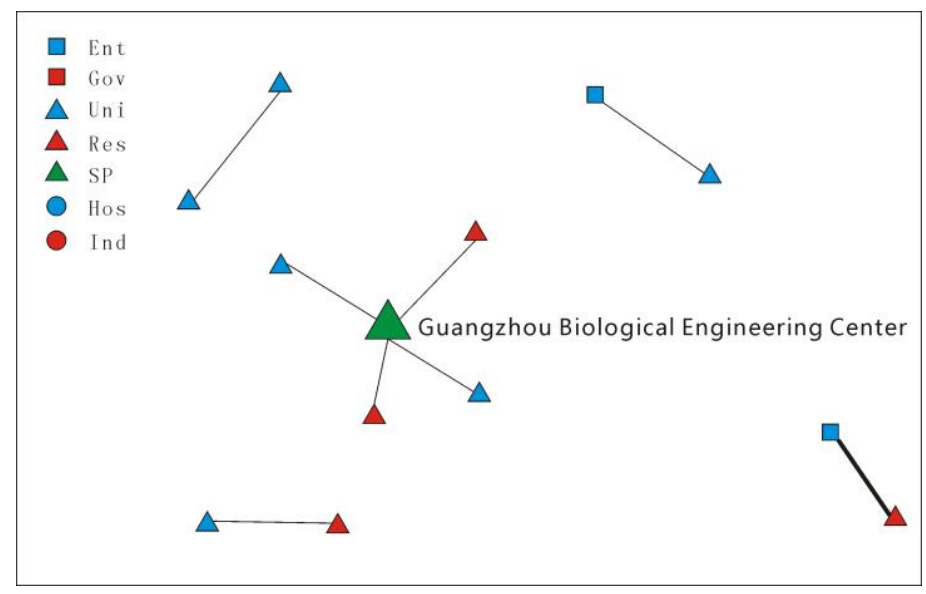

Figure 2. Network structure of paper cooperation at primary budding stage.

(2) Steady development stage (2006-2012). In 2006, the National Development and Reform Commission conferred the title of "National Biological Industry Base" on Guangzhou Development Zone, and Guangzhou also issued the "Eleventh Five-Year Plan" for the development of Guangzhou's biological industry to support industrial development. In 2007, the profits of Guangzhou biomedical listed companies began to rise. In 2008, the construction of Guangzhou Bio Island was promoted as a national strategy. In 2010, Guangzhou government promulgated a number of policy documents, including "Opinions on Promoting the Accelerated Development of the Biological Industry in Guangzhou" and "Innovative Development Plan of the Biological Industry in Guangzhou". In the same year, the first biomedical industry fund appeared in Guangzhou Bio Island. In the "Interim Measures for the Management of Development Funds of Strategic Leading Industries in Guangzhou" issued in 2012, Guangzhou's biomedical industry was listed as a key supporting industry.

The total number of cooperation patent data in this stage was 21, the scale was small (Figure 3). From the perspective of the characteristics of the network entity, scientific research institutions were the most important innovation entity. The Chinese Academy of Sciences, Sun Yat-sen University and its subordinate institutions had the strongest innovation capabilities. The Chinese Academy of Sciences even became a middleman with core knowledge. At this stage, enterprises had a small amount of cooperation and weak leadership. Private enterprises maintained close cooperative relations with universities and research institutes; from the perspective of network's structure, the concentration of network and individual was dense, the power of them to control or avoid others was weak; from the perspective of external network connections, one third of the innovation actors were from outside the region. They mainly came from areas with better development of biomedical industries such as Beijing and Jiangsu. Technological innovation has been nested in the national innovation network since the beginning. 


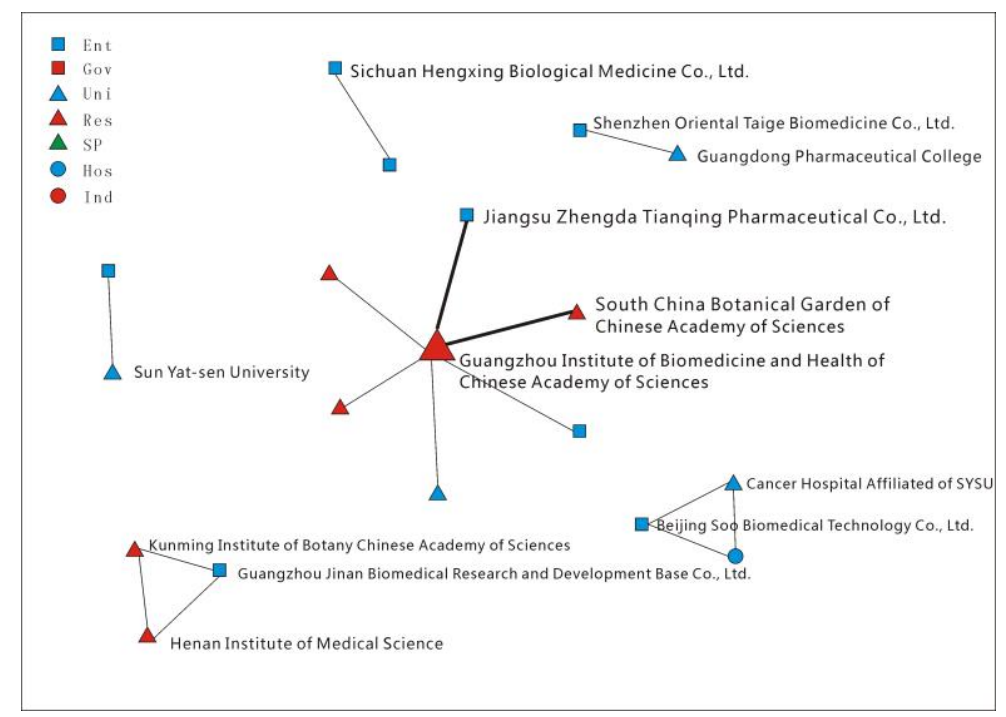

Figure 3. Network structure of patent cooperation at steady growth stage.

The total number of co-authored papers in this stage was 19,570, with an average of about 2174 papers per year. Due to its large scale, we chose to construct a topology network diagram in 2012 (at the end of the steady development stage, Figure 4) to reflect the network characteristics of the collaborative papers at this stage. From the perspective of scale, the overall form of inter-actors communication was more complicated, the number of sub-networks increased significantly, the inter-actors communication got closer, information and knowledge flowed rapidly between the subjects; from the perspective of actors in network, hospitals, governments, and individuals were the new to the network, and service agencies could hardly have a direct role. The hospital's cooperation and participation was increasing. Sun Yat-sen University, Jinan University, Southern Medical University, and Guangzhou Medical College were the most important innovation actors. Colleges and their affiliated hospitals were closely linked, but the links between colleges and other colleges' hospitals were weak. The enterprise did not occupy an important position; from the perspective of network's structure, the ability of network and actors to connect others was sharply down. The ability of entities to control or avoid was weaker; from the perspective of external network connections, the main partners were local, the cooperation with other province's firms was increasing. Most of them were hospitals and universities from Jiangsu and Zhejiang. Guangzhou was increasingly becoming an important area of the national innovation network. 


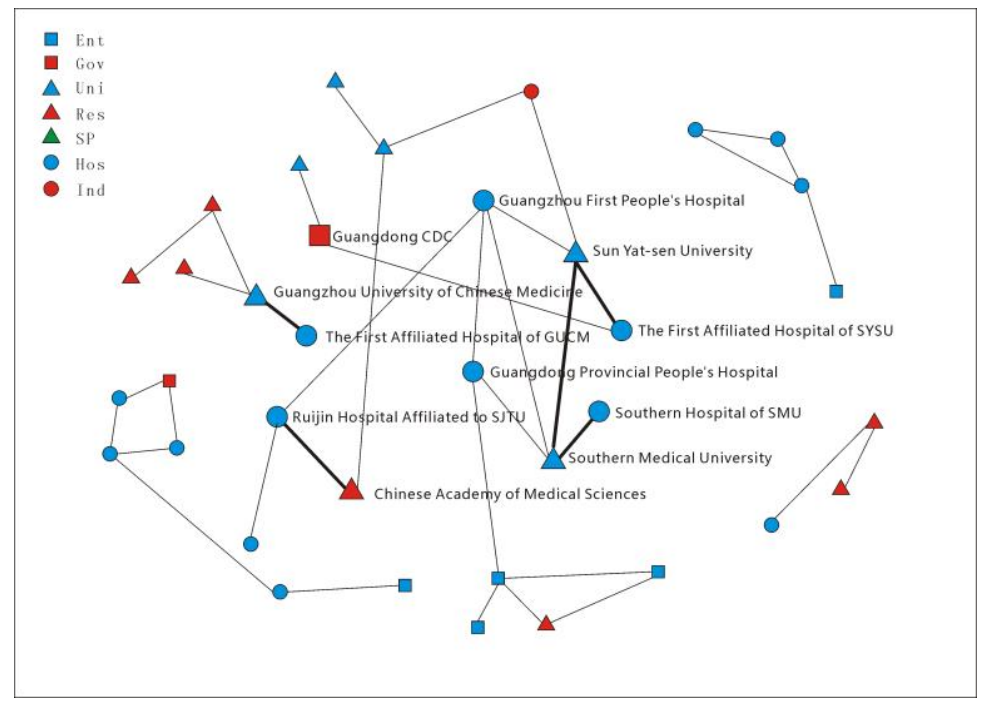

Figure 4. Network Structure of Papers Cooperation at the End of the Steady Development Stage.

(3) Rapid development stage (2013-2018). Beginning in 2013, companies and related patents in the field of biomedicine in Guangzhou were increasing, and corporate profits grew rapidly. By 2016, 19 companies had significantly increased profits. During this period, the bio island was identified as a photobiomedical professional cluster and a "National-Level Mass Entrepreneurship Technology Business Incubator". Beginning in 2017, the Guangzhou government further issued policies and documents directed at the biomedical industry to support industry development.

At this stage, there were 45 cooperation patents (Figure 5). From the perspective of scale, the scale of cooperative innovation was greatly improved compared with the previous stage, but the scale was still small. New active subgroups emerged during this period. These subgroups were mainly composed of enterprises and universities, reflecting that new innovative forces were brewing; judging from the main characteristics, enterprises occupied a more important position in cooperative innovation, and hospital participation also increased. The increase in the proportion of local enterprises indicates that market-oriented innovation capabilities were constantly increasing. University-affiliated hospitals were still one of the main forces. Guangzhou Biomedical and Health Research Institute's innovative ability was particularly outstanding; from the perspective of network's structure, the ability of network and actors to connect others was much powerful. The ability of entities to control was stronger, but the ability of entities to control was weaker; from the perspective of external network connections, other province's firms in cooperative patents accounted for a large proportion, and Guangzhou's biomedical industry was nested in the national technology innovation network. 


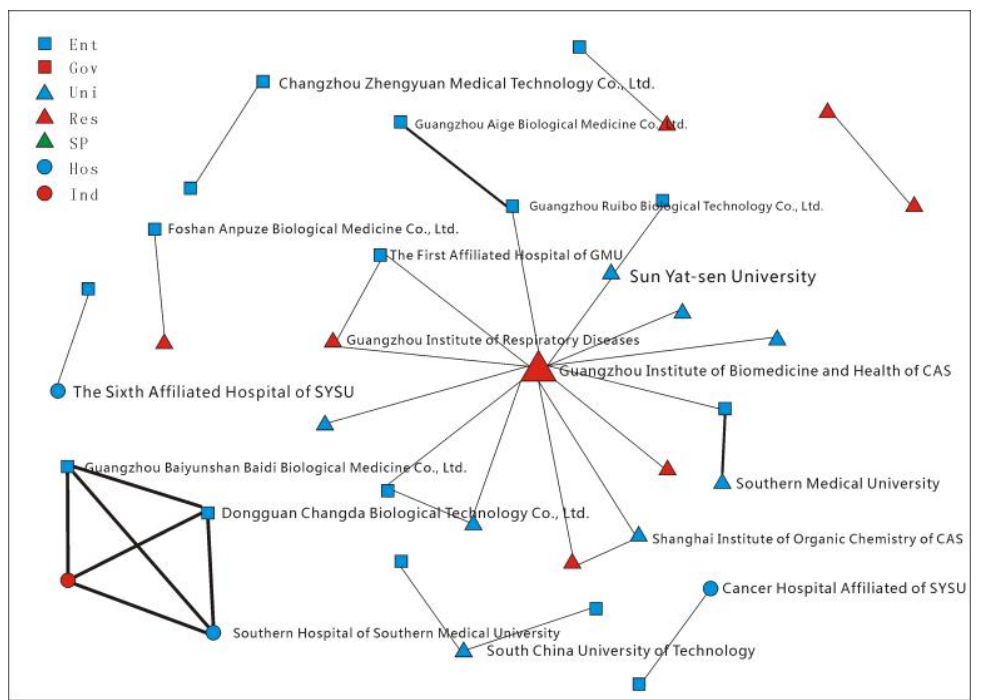

Figure 5. Network structure of patent cooperation at rapid development stage.

There were 19,659 co-authored papers in this stage, with an average of about 3277 papers per year. Based on this complex network structure, we chose the topological structure chart of 2018 to reflect the network characteristics at this stage (Figure 6). In terms of scale, the innovation network at this stage further expanded, the connections in the network were more complicated, the individual network remained stable, the advantages of the "middleman" weakened, the network began to stabilize gradually, and the network characteristics changed to some extent; from the perspective of the main characteristics, the proportion of various types of actors was basically unchanged, the participation ratio of enterprises increased, the status of the four universities in the previous stage weakened, and the innovation capabilities of other universities gradually improved; from the perspective of network's structure, the concentration of networks slightly declined, the actors' control ability improved once again, their abilities to control or avoid others was weaker than the last period; from the perspective of external network connections, hospitals outside the region, especially in Beijing, Shanghai, Zhejiang and other places, were closely connected with the subject of innovation in Guangzhou, and a small number of other province's universities also formed links with the innovators in Guangzhou. The local innovation network gradually formed a connection with the global innovation network, and local innovation capabilities were greatly improved.

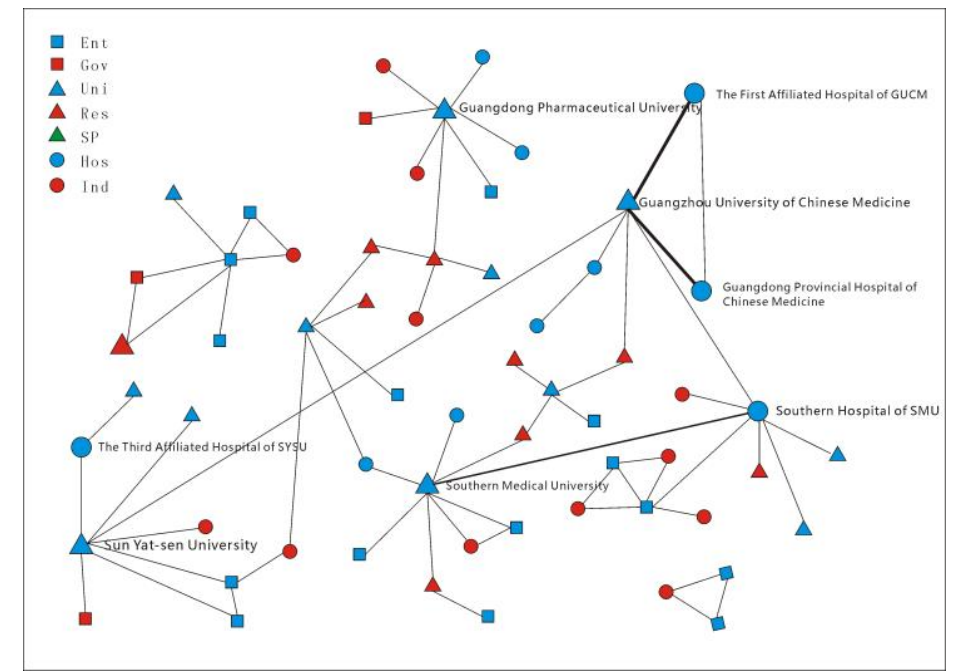

Figure 6. Network Structure of Papers Cooperation at the End of Rapid Development Stage 


\section{Proximity Mechanism of Innovation Network Evolution}

In order to reflect the mediation effect and the interaction among proximities, the authors constructed three models. Model 1 (M1) is an independent effect model, Model 2 (M2) is an intermediate effect model, and Model 3 (M3) is an interaction model. We used the related algorithms in Smart-PLS to analyze and verify whether the construction of the variables under each model at each stage meets the reliability requirements. Results are shown in Table 2 . The combination variables in each model at each stage were mostly greater than 0.6 on the Cronbach's alpha test, and all passed the 0.5 level test, which can basically reflect the situation of the latent variables; in terms of combination reliability, the reliability of combination variables was mostly greater than 0.6 , and all of them passed the 0.5 level test. The analysis reflection validity was good. The validity of some variables in some stages was low, but it was still within an acceptable range. In a word, the model variables had good construct reliability.

Table 2. Reliability tests of combined variables at each stage.

\begin{tabular}{|c|c|c|c|c|c|c|c|c|}
\hline & & & Papers & & & Patent & & \\
\hline & & & I & G & $\mathbf{N}$ & I & G & $\mathbf{N}$ \\
\hline \multirow[t]{6}{*}{ P1 } & \multirow[t]{2}{*}{ M1 } & Cronbach's alpha & 0.68 & 0.99 & 0.88 & & & \\
\hline & & Construct Reliability & 0.7 & 0.99 & 0.73 & & & \\
\hline & \multirow[t]{2}{*}{ M2 } & Cronbach's alpha & 0.68 & 0.99 & 0.88 & & & \\
\hline & & Construct Reliability & 0.71 & 0.99 & 0.73 & & & \\
\hline & \multirow[t]{2}{*}{ M3 } & Cronbach's alpha & 0.68 & 0.99 & 0.88 & & & \\
\hline & & Construct Reliability & 0.7 & 0.99 & 0.73 & & & \\
\hline \multirow[t]{6}{*}{ P2 } & \multirow[t]{2}{*}{ M1 } & Cronbach's alpha & 0.67 & 0.99 & 0.71 & 0.66 & 0.97 & 0.58 \\
\hline & & Construct Reliability & 0.89 & 0.99 & 0.96 & 0.71 & 0.99 & 0.5 \\
\hline & \multirow[t]{2}{*}{ M2 } & Cronbach's alpha & 0.67 & 0.99 & 0.73 & 0.66 & 1 & 0.6 \\
\hline & & Construct Reliability & 0.79 & 0.99 & 0.96 & 0.71 & 1 & 0.7 \\
\hline & \multirow[t]{2}{*}{ M3 } & Cronbach's alpha & 0.67 & 0.99 & 0.71 & 0.66 & 0.97 & 0.58 \\
\hline & & Construct Reliability & 0.89 & 0.99 & 0.96 & 0.71 & 0.99 & 0.5 \\
\hline \multirow[t]{6}{*}{ P3 } & \multirow[t]{2}{*}{ M1 } & Cronbach's alpha & 0.67 & 0.99 & 0.64 & 0.7 & 0.98 & 0.68 \\
\hline & & Construct Reliability & 0.84 & 0.99 & 0.69 & 0.58 & 0.99 & 0.7 \\
\hline & \multirow[t]{2}{*}{ M2 } & Cronbach's alpha & 0.67 & 0.99 & 0.64 & 0.7 & 1 & 0.68 \\
\hline & & Construct Reliability & 0.84 & 0.99 & 0.59 & 0.68 & 1 & 0.7 \\
\hline & \multirow{2}{*}{ M3 } & Cronbach's alpha & 0.67 & 0.99 & 0.64 & 0.7 & 0.98 & 0.68 \\
\hline & & Construct Reliability & 0.84 & 0.99 & 0.69 & 0.58 & 0.99 & 0.7 \\
\hline
\end{tabular}

From the perspective of the network structure, the centralization and structure hole in the collaborative papers and patents were constantly weakening, and the network's reflecting proportion in variableswas gradually increasing. This means that the monopoly capacity of individuals in the network gradually weakened, polycentric and complex connections began to appear in the network, and the overall connection of network development was also constantly improving. These changes are closely related to the knowledge characteristic and development of innovators. From the view of knowledge characteristic, the biological knowledge was codable, and the biological industry followed the Science, Technology and Innovation (STI) mode [60]. Compared to tacit knowledge, codified knowledge could much more easily be transferred among entities [33]. The innovation of biological industry was with a long-term period, mass investment and strict requests to researchers. Thus, from a long-term view, cooperation was the best choice for innovators. From the perspective of innovators' development, the number of innovators was limited in the early stage, minority entities controlled most of knowledge and resources in region, enterprises' scale was small and their innovation capability was weak, isolated innovation path strengthened the monopoly pattern. With the development, the quantity of innovators in Guangzhou biomedical industry rose, the type of innovators was much more abundant, the communication among entities was much more frequent, the innovation content was much deeper. In segmentation, actors with strong innovation capability collapsed monopolies, and became a new center (Table 3). 
Table 3. The construction of innovation network structure and the mechanism of proximities at different stages

\begin{tabular}{|c|c|c|c|c|c|c|}
\hline & & \multicolumn{2}{|l|}{ Papers } & \multicolumn{3}{|c|}{ Patents } \\
\hline & & P1 & P2 & P3 & P2 & P3 \\
\hline \multirow{3}{*}{$\begin{array}{l}\text { Network } \\
\text { Structure }\end{array}$} & Network Density & $0.67 * *$ & $0.93 * *$ & $0.92 * *$ & $-0.86 *$ & $0.93 * *$ \\
\hline & Centralization & $0.98 * *$ & $0.61 *$ & $0.52 *$ & 0.69 & $0.64 *$ \\
\hline & Structural Holes & $0.99 * *$ & $-0.45^{* *}$ & $-0.78 * *$ & $0.47^{*}$ & 0.66 \\
\hline \multirow[t]{5}{*}{ M1 } & Geographical Proximity & 0.134 * & $-0.692 *$ & $-0.547^{*}$ & $-0.692 *$ & $-0.308^{*}$ \\
\hline & Cognitive Proximity & $-0.136 * * *$ & $0.143 * *$ & $0.284 * * *$ & $0.143 * *$ & $0.660 * *$ \\
\hline & Organizational Proximity & $-0.661^{* *}$ & $-0.572 * *$ & $2.71^{* *}$ & $-0.572 * *$ & $-0.450 * *$ \\
\hline & Innovation Input & $0.501 * * *$ & $0.514^{* *}$ & $-2.711 * * *$ & $0.514^{* *}$ & $-0.582 * *$ \\
\hline & $\mathrm{R}^{2}$ & 0.835 & 0.728 & 0.92 & 0.728 & 1 \\
\hline \multirow[t]{3}{*}{ M2 } & $\begin{array}{c}\text { Geographical Proximity } \rightarrow \\
\text { Cognitive Proximity }\end{array}$ & $0.773^{* * *}$ & -0.016 & $0.603^{* *}$ & $0.366^{* *}$ & $0.074^{* *}$ \\
\hline & $\begin{array}{c}\text { Geographical Proximity } \rightarrow \\
\text { Organizational Proximity }\end{array}$ & $-0.162^{* *}$ & $0.056 * *$ & $0.753 * *$ & $-0.194 *$ & $0.674 * *$ \\
\hline & $R^{2}$ & 0.835 & 0.845 & 0.566 & 0.99 & 0.935 \\
\hline \multirow[t]{2}{*}{ M3 } & Proximities Interactions & $0.434 * * *$ & $0.389 * *$ & $1.673 * *$ & $-0.335 * * *$ & $-0.053 * *$ \\
\hline & $\mathrm{R}^{2}$ & 0.915 & 0.81 & 1 & 0.988 & 1 \\
\hline
\end{tabular}

The relationship between innovation input and network structure changed drastically during the rapid development phase. The relationship between them changed from positive to negative, and the correlation coefficient fluctuated strongly. In other words, it was increasingly difficult to invest in innovation to drive the evolution of the network structure. We believe that during the primarily budding period, the number of funds, infrastructure and actors involved in innovation was small, and those who benefited from capital and facility investment in the early stage had stronger innovation capabilities in the network and were favored by other innovators. With the accumulation of capital, talents and knowledge, entities' innovation capability was rapidly increasing. Government was the funder of research institutions. For firms, commercial revenue from Chinese remedies and generic remedies provide sustainable funding to R\&D. Capital made a great contribution to improve entities' scientific infrastructure. Recruiting talents could accelerate innovation capability and make knowledge systems more perfect in the short term. In the long term, knowledge can be accumulated in research progress; knowledge spillover among collaborations results in more and more entities getting knowledge. The gap of infrastructure, talents and knowledge was smaller among actors temporally; that is the reason why investment could not sustainably promote innovation network evolution. However, we think this relationship will reverse for researches going far in segmentation.

The relationship between geographical proximity and network structure changed from positive to negative, and the correlation coefficient gradually weakened. The relationship between geographical proximity and organizational proximity changed from negative to positive and strengthened. This means that the subject of innovation was in close contact with subjects outside the region, and at the same time, geographical proximity was increasingly playing an active role in promoting knowledge flows and organizational connections. The result is complicated, we can obtain similar evidence in empirical conclusions in other countries [61,62]. University affiliated institutions based on administrative orders often do not gather in space. However, the knowledge base and manpower professional level of the biomedical industry are high. In the early stages of industrial development, a large amount of human and finance capital was required. Excessive spatial distance was not benefit to the geographical concentration of these resources. Obviously, biological knowledge is explicit; it can be transferred across geographical space. Therefore, after the innovators' capability improves, finding cooperators inter-region is another good way for entities [63]. The relationship between cognitive proximity and network structure changed from negative to positive and gradually strengthened. This shows that the technical cognition characteristics of the cooperation partners have an important influence on the choice of innovation partners after the steady development period. Meanwhile, cognitive proximity 
was promoted by geographical proximity, but the relationship was weak in patents cooperation. The early participants in the biomedical industry were mainly traditional pharmaceutical manufacturers. The cognitive potential difference among them was small, making it difficult to form innovative cooperation. In particular spaces, face-to-face communication accelerated knowledge spillover and boosted actors' innovation capability. Since then, in order to pursue higher R\&D efficiency, the entities have put strict requests to the R\&D capabilities of its partners. Cognitive proximity becomes a necessary condition to inter-region collaboration [28]. Against the background of the increase in the total number of innovators and the enhancement of their R\&D capabilities, it has become possible to find entities with matching technological levels and professional fields. Such a cooperative relationship has been continued under the continuous prosperity of the industry and the effective flow of knowledge.

The relationship between organizational proximity and network structure continued to be negative. After the paper cooperation entered a stage of rapid development, organizational proximity became a key positive factor. The relationship between geographical proximity and organizational proximity turned from negative to positive and strengthened. This means that the nested organizational relationship between the innovators became an important factor in selecting cooperation partners, and the "guanxi" space largely replaced the "geographic" spatial distance to actors. In the early days, there were limitations on the scale and knowledge of the innovators themselves. The cooperative relationship between "top-bottom" was not a favorable direction for innovation because it could not effectively make new knowledge. With the development of industry, more and more start-ups got into the market. Some institutions grew strong, and set affiliated institutions. That was significant in Universities. In addition, with the acquisition, merger, and spin-off of enterprises, organizational relationships with higher trust became the first choice for cooperation.

The results of proximity interaction show that the relationship between proximity and network structure in collaborative academic innovation was positive, and the relationship between proximity and network structure in collaborative patent innovation was negative. This means that multidimensional proximities appeared as a complementary relationship in collaborative papers, and multidimensional proximities appeared as a substitute relationship in collaborative patent innovation. For scientific innovation, the geographical concentration of the subject promoted the exchange of knowledge, accelerates the development of actors, and continued to add subsidiary institutions in the frontier field in space; for technological innovation, the need for efficient innovation broke through the limitations of geographical space, and the main body with the enterprise as the core was more flexible in the setting of subsidiary institutions. The pursuit of frontier technology domains complicated the relationship between knowledge, institutions, and geography.

\section{Conclusions}

In order to study the topological characteristics and multi-dimensional proximity mechanism of Guangzhou biomedical industry's innovation network evolution, the authors obtained data on cooperative patents and collaborative papers from 1998 to 2018. We systematically divided the evolution of the innovation network of this case into three phases, namely, the primary budding stage from 1998 to 2005, the steady development stage from 2006 to 2012, and the rapid development stage from 2013 to 2018. Since then, we have analyzed the scale, nature and characteristics of the subjects in each stage and their relationship with the upstream and downstream of the industrial chain. Based on this, by comprehensively using Ucinet and PLS-SEM, the author further characterizes the evolutionary characteristics of the innovation network topology and analyzes the multi-dimensional proximity mechanism. Conclusions are as follows:

(1) In the Guangzhou Biomedical Industry Innovation Network, the structures of the patent cooperation network and papers cooperation network show different characteristics at each stage. At the primary budding stage, the patent network had not yet been established. The scale of early collaborative papers innovation was small, the information integration platform was the core of the network, and the external connections of the network were mainly limited to the region; in the steady 
development stage, the patent cooperation network appeared for the first time, its scale was small, colleges and universities were the core actors, enterprises' innovation ability was weak, and the network had been nested into the national innovation network from the beginning. The collaborative innovation of papers had become very large at this stage. Colleges and universities were the most important subject of innovation. The affiliated hospitals were closely connected with colleges and universities. The network was beginning to nest in the country. During the rapid development stage, the scale of the patent innovation network was still limited, the status of enterprises in the network had been enhanced, and the school-enterprise relationship had been strengthened. In the process of interacting with national innovation entities, other places companies were important entities. The academic innovation network continued to expand. Universities were the most important innovation subjects, and hospitals outside the region were important partners. Network connections had begun to cross national boundaries.

(2) The multi-dimensional proximities evolution mechanism of Guangzhou's biomedical industry innovation network shows phase differences. In general, the evolution of the network structure has shifted from monopoly to decentralized, the integrated connection of the network has become closer, there have been polycentric and complex connections. In the primary budding stage, the number of innovation subjects was small, research institutions had almost no independent affiliated institutions, and limited knowledge could hardly help the actors to establish cooperative relationships. Therefore, geographical proximity played an important role in this stage; during the period of steady development, the spillover of knowledge accompanied the increase in the number of subjects in the local area, and the improvement of the subject's research and development capabilities placed higher demands on knowledge. Cognitive proximity began to play a more active role and continued to the rapid development stage in effective knowledge exchange; during the period of rapid development, the actor's innovation ability got greater. In order to protect knowledge, subjects were more willing to cooperate in a relationship of mutual trust. Organizational proximity was crucial during this period.

Our research put the knowledge about proximities and innovation network evolution in China further. Although the evidences from China's city innovation networks make researchers believe proximities may be much suitable for SKN instead of TKN [27], we hold a different attitude to this opinion. This also shows the necessity to researchers the importance of multi-scale and multi-industry studies. On the one hand, this article points out that universities play a most important role in SKN and TKN. This is on the opposite side of the evidence from developed countries, scholars think enterprises are the critical actors to analyze innovation networks [19]. For catch-up nations like China, universities are the main sources of knowledge, they are funded by government, so that their R\&D abilities are much powerful than companies. In fact, it is not a bad thing like some scholars said [64], because enterprises have got progress with the help of universities; on the other hand, we discover that geographical proximity is the initial energy of innovation evolution, cognitive proximity puts a positive effect on it, and organizational proximity is the motivation in rapid development stage. Guangzhou's biological industry is weak at the budding time, it is not particular in China [65]. Local governments prefer concentrated investing at short time to make some universities grow up. That puts them to be these entities under spotlights in innovation networks. Meanwhile, innovation in Guangzhou biomedical industry is to problem-solving, the entities are radical in innovation [18]. Thus, naturally, cognitive distance is critical after innovators are stronger. Considering the knowledge of biomedical industry are codeable [33], it is not difficult to be transferred across regions. Organizational proximity is the most important factor in short term, however, collaborating motivation will finally return to the actors' research directions.

In order to accelerate the sustainable development of the Guangzhou Biopharmaceutical Industry Innovation Network, from the perspective of cooperation content, we propose the following policy recommendations. In the view of scientific cooperative innovation, we believe that there is still a large gap between the Guangzhou innovation infrastructure and the international frontier level; the government should continue to promote innovation investment and improve research infrastructure. 
The science and technology department should encourage medical institutions in specific clinical directions to cooperate with hospitals outside the region, and encourage competent universities to cooperate with overseas universities to promote the upgrading of knowledge in the region. Regarding technological cooperation and innovation, in our survey, some companies reported that it is "difficult to contact universities in Higher Education Mega Centre", and some companies reported that "there are significant differences in management and operation between the two sides", but "the project is very important to our innovation". We believe that the local government can boost the innovation cooperation between enterprises and universities by setting up a science and technology exchange service platform and holding school-enterprise exchange forums. In fact, making collaboration is not an easy thing. Researchers not only worry the private information security of patients, but also worry others misuse data or plagiarize their intellectual achievement. In some field, innovators also face ethical issues. Embryonic is a controversial research field. Fuzzy definition makes researchers conservative in material selection; some research is not deep enough [66]. Therefore, for government, building an ethical and innovation-friendly regulation is as important as improving local intellectual property system. Improving local legal support will help entities establish connections.

Author Contributions: Conceptualization, Q.Q.; methodology, data curation, formal analysis Y.Z; writing_-original draft preparation, K.Z.; writing-review and editing, K.Z. and Q.Q.; funding acquisition, Q.Q. All authors have read and agreed to the published version of the manuscript.

Funding: This article is funded by National Natural Science Foundation of China, the number is 41771127.

Conflicts of Interest: The authors declare no conflict of interest.

\section{References}

1. Feldman, M.P. The Geography of Innovation; Kluwer Academic Publishers: Dordrecht, The Netherlands, 1994.

2. Rothwell, R. Successful industrial innovation: Critical factors for the 1990s. R D Manag. 1992, 22, 221-240. [CrossRef]

3. Asheim, B. The changing role of learning regions in the globalizing knowledge economy: A theoretical re-examination. Reg. Stud. 2012, 46, 993-1004. [CrossRef]

4. Freeman, L.C. Networks of innovators: A synthesis of research issues. Res. Policy 1991, 20, 499-514. [CrossRef]

5. Granovetter, M.S. The strength of weak ties: A network theory revisited. Sociol. Theory 1983, 11, 201-233. [CrossRef]

6. Martin, R.; Sunley, P. Deconstructing clusters: Chaotic concept or policy panacea? J. Econ. Geogr. 2003, 33, 5-35. [CrossRef]

7. Huggins, R.; Thompson, P. A Network-based view of regional growth. J. Econ. Geogr. 2013, 14, 511-545. [CrossRef]

8. Ter Wal, A.L.J. Cluster emergence and network evolution: A longitudinal analysis of the inventor network in Sophia-Antipolis. Reg. Stud. 2013, 47, 651-668. [CrossRef]

9. Glückler, J.; Doreian, P. Editorial: Social network analysis and economic geography—Positional, evolutionary and multi-level approaches. J. Econ. Geogr. 2016, 16, 1123-1134.

10. Graf, H.; Krueger, J.J. The performance of gatekeepers in innovator networks. Ind. Innov. 2011, 18, 69-88. [CrossRef]

11. Morgan, K. Regional advantage: Culture and competition in Silicon Valley and route 128: AnnaLee Saxenian. Res. Policy 1996, 25, 484-485. [CrossRef]

12. Hoekman, J.; Frenken, K.; Tijssen, R.J.W. Research collaboration at a distance: Changing spatial patterns of scientific collaboration within Europe. Res. Policy 2010, 39, 662-673. [CrossRef]

13. Turkina, E.; Van Assche, A.; Kali, R. Structure and evolution of global cluster networks: Evidence from the aerospace industry. J. Econ. Geogr. 2016, 16, 1211-1234. [CrossRef]

14. Scherngell, T.; Hu, Y. Collaborative knowledge production in China: Regional evidence from a gravity model approach. Reg. Stud. 2011, 45, 755-772. [CrossRef]

15. Hoekman, J.; Frenken, K.; Van Oort, F. The geography of collaborative knowledge production in Europe. Ann. Reg. Sci. 2009, 43, 721-738. [CrossRef] 
16. Boschma, R. Proximity and innovation: A critical assessment. Reg. Stud. 2005, 39, 61-74. [CrossRef]

17. Balland, P.-A. Proximity and the evolution of collaboration networks: Evidence from research and development projects within the global navigation satellite system (GNSS) industry. Reg. Stud. 2012, 46, 741-756. [CrossRef]

18. Xu, J.; Yang, F.F.; Xue, D. The geography of knowledge sourcing, personal networks, and innovation effects: Evidence from the biomedical firms in Guangzhou, China. Sustainability 2019, 11, 3412. [CrossRef]

19. Maskell, P. The firm in economic geography. Econ. Geogr. 2001, 77, 329-344. [CrossRef]

20. Graf, H.; Henning, T. Public research in regional networks of innovators: A comparative study of four East German regions. Reg. Stud. 2009, 43, 1349-1368. [CrossRef]

21. Liefner, I. Funding, resource allocation, and performance in higher education systems. High Educ. 2003, 46, 469-489. [CrossRef]

22. Owen-Smith, J.; Powell, W.W. Knowledge networks as channels and conduits: The effects of spillovers in the Boston biotechnology community. Organ. Sci. 2004, 15, 5-21. [CrossRef]

23. Huggins, R.; Prokop, D. Network structure and regional innovation: A study of university-industry ties. Urban Stud. 2017, 54, 931-952. [CrossRef]

24. Glueckler, J. Economic geography and the evolution of networks. J. Econ. Geogr. 2007, 77, 619-634. [CrossRef]

25. Graf, H.; Kalthaus, M. International research networks: Determinants of country embeddedness. Res. Policy 2018, 47, 1198-1214. [CrossRef]

26. Boschma, R.A.; Ter Wal, A.L.J. Knowledge networks and innovative performance in an industrial district: The case of a footwear district in the south of Italy. Ind. Innov. 2007, 14, 177-199. [CrossRef]

27. Li, D.; Wei, Y.D.; Wang, T. Spatial and temporal evolution of urban innovation network in China. Habitat Int. 2015, 49, 484-496. [CrossRef]

28. Pond, R.; Van Oort, F.; Frenken, K. The geographical and institutional proximity of research collaboration. Pap. Reg. Sci. 2007, 86, 423-443. [CrossRef]

29. Torre, A.; Rallet, A. Proximity and localization. Reg. Stud. 2005, 39, 47-59. [CrossRef]

30. Bunnell, T.G.; Coe, N.M. Spaces and scales of innovation. Prog. Hum. Geogr. 2001, 25, 569-589. [CrossRef]

31. Knoben, J.; Oerlemans, L.A.G. Proximity and inter-organizational collaboration: A literature review. Int. J. Manag. Rev. 2006, 88, 71-89. [CrossRef]

32. Whittington, K.B.; Owen-Smith, J.; Powell, W.W. Networks, propinquity, and innovation in knowledge-intensive industries. Adm. Sci. Q. 2009, 54, 90-122. [CrossRef]

33. Bathelt, H.; Malmberg, A.; Maskell, P. Clusters and knowledge: Local buzz, global pipelines and the process of knowledge creation. Prog. Hum. Geogr. 2004, 28, 31-56. [CrossRef]

34. Pan, R.K.; Kaski, K.; Fortunato, S. World citation and collaboration networks: Uncovering the role of geography in science. Sci. Rep. 2012, 2, 902. [CrossRef]

35. Nooteboom, B. Learning by interaction: Absorptive capacity, cognitive distance and governance. J. Manag. Gov. 2000, 44, 69-92. [CrossRef]

36. Giuliani, E.; Bell, M. The micro-determinants of meso-level learning and innovation: Evidence from a Chilean wine cluster. Res. Policy 2005, 34, 47-68. [CrossRef]

37. Boschma, R.A.; Lambooy, J.G. Knowledge, market structure, and economic coordination: Dynamics of industrial districts. Growth Chang. 2002, 33, 291-311. [CrossRef]

38. Cohen, W.M.; Levinthal, D.A. Absorptive Capacity: A new perspective on learning and innovation. Adm. Sci. Q. 1990, 35, 128-152. [CrossRef]

39. Balland, P.; Antonio Belso-Martinez, J.; Morrison, A. The dynamics of technical and business knowledge networks in industrial clusters: Embeddedness, status, or proximity? Econ. Geogr. 2016, 92, 35-60. [CrossRef]

40. Nooteboom, B.; Van Haverbeke, W.; Duysters, G.; Gilsing, V.; Van den Oord, A. Optimal cognitive distance and absorptive capacity. Res. Policy 2007, 36, 1016-1034. [CrossRef]

41. Asheim, B.T.; Isaksen, A. Regional innovation systems: The integration of local 'sticky' and global 'ubiquitous' knowledge. J. Technol. Transf. 2002, 27, 77-86. [CrossRef]

42. Elfring, T.; Hulsink, W. Networks in entrepreneurship: The case of high-technology firms. Small Bus. Econ. 2003, 21, 409-422. [CrossRef]

43. Miorner, J.; Zukauskaite, E.; Trippl, M.; Moodysson, J. Creating institutional preconditions for knowledge flows in cross-border regions. Environ. Plan. C Politics Space 2018, 36, 201-218. [CrossRef] 
44. Caragliu, A.; Nijkamp, P. Space and knowledge spillovers in European regions: The impact of different forms of proximity on spatial knowledge diffusion. J. Econ. Geogr. 2016, 16, 749-774. [CrossRef]

45. Broekel, T.; Mueller, W. Critical links in knowledge networks-What about proximities and gatekeeper organisations? Ind. Innov. 2018, 25, 919-939. [CrossRef]

46. Shang, Q.; Poon, J.P.H.; Yue, Q. The role of regional knowledge spillovers on China's innovation. China Econ. Rev. 2012, 23, 1164-1175. [CrossRef]

47. Liang, L.; Zhu, L. Major factors affecting China's inter-regional research collaboration: Regional scientific productivity and geographical proximity. Scientometrics 2002, 55, 287-316. [CrossRef]

48. Li, Y.; Wang, X. Innovation in suburban development zones: Evidence from Nanjing, China. Growth Chang. 2019, 50, 114-129. [CrossRef]

49. Lin, G.C.S.; Yang, F.F.; Hu, F.Z.Y. The new geography of information and consulting services in China: Comparing Beijing and Guangzhou. Habitat Int. 2012, 36, 481-492. [CrossRef]

50. Wang, C.C.; Lin, G.C.S. The growth and spatial distribution of China's ICT industry: New geography of clustering and innovation. Issues Stud. 2008, 44, 145-192.

51. Liu, N.; Wang, J.; Song, Y. Organization mechanisms and spatial characteristics of urban collaborative innovation networks: A case study in Hangzhou, China. Sustainability 2019, 11, 5988. [CrossRef]

52. Yan, W.; Wu, Y.; Pan, Y.; Ma, Z.; Rousseau, R. Scientific collaboration in China as reflected in co-authorship. Scientometrics 2005, 62, 183-198.

53. Almeida, P.; Kogut, B. Localization of knowledge and the mobility of engineers in regional networks. Manag. Sci. 1999, 45, 905-917. [CrossRef]

54. D'Este, P.; Guy, F.; Iammarino, S. Shaping the formation of university-industry research collaborations: What type of proximity does really matter? J. Econ. Geogr. 2013, 13, 537-558. [CrossRef]

55. Agrawal, A.; Cockburn, I.; McHale, J. Gone but not forgotten: Knowledge flows, labor mobility, and enduring social relationships. J. Econ. Geogr. 2006, 66, 571-591. [CrossRef]

56. Basberg, B.L. Patents and the measurement of technological change: A survey of the literature. Res. Policy 1987, 16, 131-141. [CrossRef]

57. Lin, L. Multi-Dimensional Proximities and Industrial Cluster Innovation; Peking University Press: Beijing, China, 2014. Available online: http://www.pup.cn/bookDetail?name=\%25E5\%25A4\%259A \%25E7\%25BB $\% 25 B 4 \%$ 25E9\%2582\%25BB $\% 25 \mathrm{E} 8 \% 25 \mathrm{BF} \% 2591 \% 25 \mathrm{E} 6 \% 2580 \% 25 \mathrm{~A} 7 \% 25 \mathrm{E} 4 \% 25 \mathrm{~B} 8 \% 258 \mathrm{E} \% 25 \mathrm{E} 4 \% 25 \mathrm{BA} \% 25 \mathrm{~A} 7 \%$ 25E4\%25B8\%259A \%25E9\%259B\%2586\%25E7\%25BE\%25A4\%25E5\%2588\%259B \%25E6\%2596\%25B0\&id= ce173f45185f11e9805800163e0a6607\&0.5613959612511303 (accessed on 13 March 2020).

58. Hair, J.F.; Ringle, C.M.; Sarstedt, M. PLS-SEM: Indeed a silver bullet. J. Mark. Theory Pract. 2011, 19, 139-152. [CrossRef]

59. Jaffe, A.B.; Henderson, R.M.; Trajtenberg, M. Geographic Localization of Knowledge Spillovers as Evidenced by Patent Citations; Social Science Electronic Publishing: New York, NY, USA, 1993.

60. Jensen, M.B.; Johnson, B.; Lorenz, E.; Lundvall, B.A. Forms of knowledge and modes of innovation. Res. Policy 2007, 36, 680-693. [CrossRef]

61. Ter Wal, A.L.J. The dynamics of the inventor network in German biotechnology: Geographic proximity versus triadic closure. J. Econ. Geogr. 2014, 14, 589-620. [CrossRef]

62. Balland, P.; De Vaan, M.; Boschma, R. The dynamics of interfirm networks along the industry life cycle: The case of the global video game industry, 1987-2007. J. Econ. Geogr. 2013, 13, 741-765. [CrossRef]

63. Binz, C.; Truffer, B. Global innovation systems-a conceptual framework for innovation dynamics in transnational contexts. Res. Policy 2017, 46, 1284-1298. [CrossRef]

64. Liang, X.; Liu, A.M.M. The evolution of government sponsored collaboration network and its impact on innovation: A bibliometric analysis in the Chinese solar PV sector. Res. Policy 2018, 47, 1295-1308. [CrossRef]

65. Peng, F.; Zhang, Q.; Han, Z.; Ding, Y.; Fu, N. Evolution characteristics of government-industry-university cooperative innovation network of electronic information industry in Liaoning province, China. Chin. Geogr. Sci. 2019, 29, 528-540. [CrossRef]

66. Owen-Smith, J.; Scott, C.T.; McCormick, J.B. Expand and regularize federal funding for human pluripotent stem cell research. J. Policy Anal. Manag. 2012, 31, 714-722. [CrossRef] [PubMed]

(C) 2020 by the authors. Licensee MDPI, Basel, Switzerland. This article is an open access article distributed under the terms and conditions of the Creative Commons Attribution (CC BY) license (http://creativecommons.org/licenses/by/4.0/). 